\title{
Quality improvement by peer review in primary care: a practical guide
}

\author{
Richard Grol
}

The reluctance of people to have their work evaluated is closely linked with their reluctance to comment on, or to complain about the behaviour of others. Most people 'live and let live'. This attitude, we admit, is not only understandable: it is invaluable. Social life depends on it. Who should throw the first stone? Who indeed can really distinguish between an honest mistake and culpable negligence? This is why we believe that efforts to improve performance must come from a desire for self-improvement, a desire based on an essentially ethical insight. Audit must not be part of a disciplinary instrument; it must be a tool for learning by feedback. ${ }^{1}$

One of the most challenging questions in quality of care today is how to change the practice performance of care providers, and effective and feasible methods of improving performance are urgently required. Peer review in small groups or teams of care providers seems to provide such a method ${ }^{2}$ and it matches the "profile" of effective behaviour change in health care, as found in the literature. Elements of this profile are as follows.

- Care providers are subject to powerful and potentially determining influences from opinion leaders and influential respected peers in their professional network and their local setting. ${ }^{3-12}$ These influences can and should be used in bringing about change

- Peer audit and feedback as well as mutual support by colleagues are crucial in inducing change $\mathrm{e}^{13-19}$

- A combination of interventions is probably more effective in improving care than separate interventions ${ }^{15} 1720$

- The methods of quality improvement preferred by many care providers in primary care are small scale activities which relate to their own work, that include personal contact with colleagues, and that do not take too much time and do not interfere unduly with daily routines. These activities should include reflection on performance and learning new skills and they should reduce uncertainty in daily work. ${ }^{21-25}$

Peer review is defined as a "continuous, systematic, and critical reflection by a number of care providers, on their own and colleagues' performance, using structured procedures, with the aim of achieving continuous improvement of the quality of care." This definition is consistent with recent views on continuous quality improvement which see quality assurance and audit as methods of continuous learning and ask practitioners to be open to evaluation and comments on performance. ${ }^{26-28}$
The effectiveness of peer review is evident in several studies, ${ }^{13} 1429-31$ but many care providers remain hesitant about becoming involved in peer review. This paper describes the method of peer review, its characteristics and opportunities, and some of the difficulties of setting it up.

\section{What is peer review?}

Peer review literally means evaluation by a colleague. It is used to describe, for instance, the assessment of manuscripts for scientific journals or the assessment of research proposals. Used as an approach to control performance in health care in the United States in the 1970s and '80s, peer review gained a dubious reputation among care providers there. In quality improvement in Europe peer review is currently understood as a structured process with particular characteristics.

- Peer review is undertaken by two or more care providers (usually a group or a team of 5-10), for an extended period, with regular meetings and activities (at least once a month)

- A variety of subjects, interventions, and methods are used in a planned and structured way

- Setting criteria, data collection, evaluation of each other's work, exchange of experiences, developing guidelines, solving problems in practice, and making specific arrangements for achieving changes may all be included in the process

- Collaboration with respected peers and their evaluation and support are central to the process.

Box 1 outlines the general structure of peer review, including the quality improvement cycle and box 2 lists examples of peer review methods, which each provide a different emphasis. A systematic and continuous peer review process can include all of the approaches described, depending on the particular topic. Ideally, the different approaches are integrated as part of a long term process of continuous quality improvement - a process of continuously selecting problems, formulating goals for good care, measuring actual care, selecting necessary changes, implementing them, and performing a follow up.

WHO ARE PEERS?

"A peer is a person who is equal in any stated respect". ${ }^{32}$ Usually in the same branch of health care provision, with comparable 
Preparing for peer review

- acquiring skills and becoming acquainted with it

- making practical and organisational arrangements for peer review

- formulating a plan for $6-12$ months

Selecting suitable topics

-identifying relevant quality problems

- discussing and selecting topics for peer review

- precisely defining these topics

Selecting and agreeing criteria

-agreeing on general goals for improving practice

- selecting crucial indicators for these goals

- defining the criteria/targets for desirable performance

Observing practice and evaluating care

- selecting or developing instruments and procedures for data collection and analysis

- collecting data on practice performance

- analysing these data: comparing performance with targets, looking at comparisons with colleagues and at trends

- giving understandable and well organised feedback to each other

Planning and implementing changes

-identifying areas for change; selection of individual or practice goals for improvement

-identifying specific problems and barriers to achieving these improvements

- planning actions and selecting strategies to implement changes and solve problems

- carrying out this plan

Follow up

- analysing progress/success

- analysing barriers, when no progress has been made

- further planning

Box 1 Structure of peer review and quality improvement cycle

Consensus development - a structured process aimed at developing agreement on criteria and targets for improvement

Evaluation of performance/audit - emphasis on setting criteria and targets for clinical performance, collecting data, evaluating care, and presentation of feedback

Practice visits - observation in the practice by a colleague with an emphasis on evaluating premises, practice management and performance, and implementing changes

Industrial quality circle - emphasis on identifying and defining quality problems and finding concrete solutions to these problems

Small group education - continuing medical education or skills training on specific subjects in a peer review group

Box 2 Some peer review methods

experience or training, peers may be colleagues of the same or different disciplines working together in a practice (for example, doctors, nurses, receptionists, managers, midwives, etc) or hospital unit or they may be care providers working together in local or regional unidisciplinary or multidisciplinary groups.

\section{Experience of peer review in primary care}

How should peer review be initiated and managed in primary care? The different models that have been tried in the past decade may help care providers in primary care to develop their own peer review programme. Experiences in the Netherlands, the United Kingdom, Republic of Ireland, and Germany are outlined briefly below.

\section{DUTCH HXPERIENCI:}

The first experiments with peer review in primary care were by myself and others in the early ' 80 s in the district of Nijmegen ${ }^{2} 14^{33}$ in groups of about 10 general practitioners (GPs) following a structured programme of monthly sessions. The groups used guidelines, developed in consensus meetings of experienced GPs, and various review methods (such as audiotaped consultations, self recording, and practice visits). At first there was intensive guidance, which gradually was reduced. All 332 doctors involved in the education of undergraduates and postgraduates were targeted with written information, telephone cells, and meetings where opinion leaders and doctors who had already experienced peer review, explained the programme. Thus, the approach was gradual and personal entailing between one and two years' preparation. Altogether, 234 GPs (71\%) were involved, working in 22 groups: each group ran for at least 12 months and participation in the meetings was, on average, $80 \%$. After a pilot period in which the method was further developed (see box 1) the programme was evaluated; complete evaluation data were available for $131(56 \%)$ participants.

The GPs' opinions of the meetings were generally very positive; specific problems with the peer review process in the first phase were problems of investment of time; receiving criticism, meeting criteria, and making practical arrangements for participation. Although most of these problems gradually decreased with time, the problems of meeting performance criteria and criticising colleagues gradually increased. The participants reported many changes in their performance due to the peer review, as well as an increase in their self confidence and satisfaction in working as a GP. When asked about the factors most important in bringing about changes in performance (by selecting one factor out of 12 and adding extra factors if necessary) they indicated as the most important factors exchanging practice experiences with colleagues, awareness of gaps in performance, and being informed about new guidelines for practice performance (table 1).

Actual changes in the performance of a group of 43 GPs before the programme and 6-12 months afterwards were also measured. ${ }^{1+}$

Table 1 Most important factors in peer review process that influenced change among 131 general practitioners

\begin{tabular}{lr}
\hline Factor & \\
\hline Exchanging practice experiences with colleagues & 25 \\
Awareness of gaps in performance & 24 \\
Being informed on new guidelines & 21 \\
Learning how to evaluate performance & 9 \\
Discovering that colleagues have failings too & 7 \\
Learning about practice routines of colleagues & 7 \\
Other factors & 7 \\
\hline Total & 100 \\
\hline
\end{tabular}


A trained observer visited the participants at their surgeries and collected data on consultations. For each GP 30-35 consultations and 400-700 specific medical activities were assessed, using the consensus guidelines. Changes were found in history taking, patient education, involving patients in the consultation, follow up, and prescribing drugs.

The results of the first study were so positive that the Dutch Association of GPs decided to make peer review in local groups compulsory as part of a new quality assurance and recertification scheme. Local GP groups are now being prepared for this new task, with training in leading and supervising peer review being provided for group representatives, each representative receiving three training sessions on chairing group sessions, how to set up a peer review programme, and an introduction to specific methods for peer review. Once each has started to work with their own group further meetings are held to discuss any problems which emerge. The national guidelines for general practice care, published in 1989, form the basis of the peer review methods which are used in the training. ${ }^{34}$

This new approach to implementing peer review was evaluated in the south eastern part of the Netherlands. ${ }^{35}$ In all, 28 GPs from this district have so far been trained to lead peer groups; 218 participant GPs from their groups (response $85 \%$ ) completed evaluation questionnaires after one year in the peer group. Overall the programme was evaluated very positively and $90 \%$ of participants thought it valuable for the daily work of GPs. Less than $10 \%$ did not particularly value the experience. Asked to evaluate the supervisory role of their trained group representative, the participants generally judged their leader positively, although there were criticisms about handling disagreements in the group, supervising the time schedule, application of methods, and stimulating self responsibility in the group members (table 2). The GPs were asked to compare four well known methods for quality improvement and education for GPs with regard to their perceived effectiveness: peer review in small groups, local continuing medical education meetings, national or regional courses, and meetings between GPs and hospital specialists. Only GPs who had recent experience with the methods were involved in the analysis. Peer review was evaluated as being much more (2-3 times) effective than the other methods in increasing the awareness of the GPs' own

Table 2 Opinions on group leader among 218 group participants. Figures are percentages

Very good Good or acceptable Moderate or poor

\begin{tabular}{llll}
\hline Not dominating, distant role & 32 & 59 & 9 \\
Creating a safe atmosphere & 30 & 64 & 6 \\
Clear arrangements for meetings & 30 & 56 & 14 \\
Emphasis on informal contact & 26 & 60 & 14 \\
Sufficient involvement of all participants & 23 & 69 & 8 \\
Supervision of the time schedule & 19 & 63 & 18 \\
Stimulating self responsibility & 19 & 66 & 15 \\
Information on programme & 18 & 75 & 7 \\
Instructions on exercises & 16 & 73 & 11 \\
Adequate application of peer review methods & 14 & 71 & 15 \\
Solving disagreements in group & 10 & 64 & 26 \\
\hline
\end{tabular}

performance and in promoting change in practice routines. Finally, when asked whether they would continue with peer review in the next year $82 \%$ of the GPs were certain of continuing and $15 \%$ stated that they would probably continue.

PEER REVIEW IN UNITED KINGDOM

A model for small group peer review was developed in the North of England Study of Standards and Performance. ${ }^{29}$ The emphasis in these groups was on standard setting. In all, 92 practitioners from the district took part, in 10 small groups, each of which set a standard for one of five common childhood conditions (acute cough, acute vomiting, bedwetting, itchy rash, and recurrent wheezy chest). The members of each group also received a standard devised by another group for another of the five conditions. Participants who set a clinical standard proved to change their prescribing patterns in directions consistent with those standards and maintained the changes for up to two years. Four of these groups were observed and recorded during a total of 19 meetings. ${ }^{36}$ Features of the structure, the task, and the functioning of the group showed an influence on the educational experience of the group members. Care providers taking part in peer review groups were proved to require specific skills to facilitate meetings, such as leadership skills, communication skills, and skills to manage conflict and resolve problems in the groups.

EXPERIENCE IN REPUBLIC OF IRELAND

In the Republic of Ireland a network of part time GP tutors has been developed in the past decade. ${ }^{37}$ Each tutor serves the $60-80$ GPs in his or her local area and facilitates and organises ongoing small group continuing medical education and peer review. Full national coverage has been recently achieved, and almost $70 \%$ of the 1900 GPs in Ireland have agreed to participate in the small group sessions. The government funds the tutors for 2 to 3 days' work a week and tutors receive regular training to maintain their skills in facilitating. A small group review method is used to assess performance - sometimes in relation to explicit guidelines - with the intention of changing the doctor's performance. Case discussions, small scale data collection, video consultation analysis, practice visits, and simulated problems are the most important methods used; others include practice activity analysis, use of external expert resources, and hands on skills teaching. The methods are continuously refined, particularly the methodology for implementing changes in practice performance and for follow up. A project is currently being undertaken, which tries to relate specific peer review activities to changes in prescribing.

GERMAN EXPERIENCE

Peer review ('quality circles') became fashionable in ambulatory care in Germany at the end of the ' $80 \mathrm{ss}^{38}$ Projects aimed at experimenting with small group review started in various 
locations in the past five years, and in 1993, 16 different peer review projects were recorded across Germany, with about 400 to 450 participating doctors in ambulatory care, ${ }^{39}$ covering various methods (practice activity analysis, videotaped consultations, chart audit, case analysis, etc) and topics (asthma, diabetes, low back pain, doctor-patient communication, etc). This development is underpinned by new rules and guidelines issued in 1993 from the Association of Sickness Fund Doctors (KBV), which make obligatory internal quality improvement by professionals in ambulatory care, by peer review or quality circles. ${ }^{40}$ University academic departments of general practice in Hannover and Göttingen support the development with a training course for group supervisors or moderators in implementing peer review in local or regional groups of doctors. About 200 care providers from ambulatory care have so far been trained to perform this role (J Szecsenyi, personal communication). A handbook ${ }^{39}$ and a videotape on principles and methods of peer review support this course.

\section{Setting up peer review}

Setting up peer group review succesfully requires good preparation and management. Experiences in Europe have provided useful indicators of important points for recruitment of GPs, promoting a positive attitude towards peer review, the methodology of peer review, stimulating change in performance, and the organisation of the process.

RECRUITMENT AND MOTIVATION

Care providers are often motivated but at the same time somewhat hesitant to participate in peer review, for several reasons. Generally, most care providers work alone and are only partly accountable to others. Participation in peer reviews gives colleagues the opportunity to look at an individual practitioner's work and offer their criticism, which, although it may be helpful and even positive, may also evoke resistance - owing to fear of being shown up in front of others, fear of discovering weaknesses, or fear of being branded as bad care providers. Other problems relate to the process of setting criteria and changing performance. Many practitioners will not be willing to relinquish their clinical freedom in managing patients and their problems; there may also be uncertainty about the procedures and methods of peer review and whether peer review will lead to worthwhile results. Participants may also introduce all kinds of practical and financial objections, which may partly be the result of a certain amount of resistance, and they may, erroneously, see peer review as a method of assessing and controlling their performance rather than an approach to continuous improvement and learning.

All these objections should be taken into account when peer review activities are being promoted. Thorough preparation and motivation of care providers is crucial: small scale or model projects are an appropriate way to start; care providers should be asked to partici-
Attention to group functioning - creating a constructive and open atmosphere

Discussing expectations and fears - participants should be offered the opportunity to express their feelings and these should be taken seriously; arrangements on the manner of conduct and on giving mutual criticism are helpful

Offering structure - giving insight into the programme and the review methodologies and using well designed methods that are clearly understood by the participants

Discussing the aims of per review - it should be made clear that peer review is an educational exercise, a method for achieving improvements in care for patients with mutual support for care providers

Box 3 Mochanisms for improving group motiation

pate by colleagues whom they respect, and experienced participants should be available to provide information on the peer review process and to answer questions. The development of the peer group based quality improvement programme in general practice in the Republic of Ireland provides a good example of how to set up peer review ( $M$ Boland, personal communication). Firstly, all key people in one district were visited, during which practice problems and educational needs of potential participants were discussed. Then they were invited to start an experimental peer review group. These first participants spent time developing the methods for peer group review and then each started their own peer review group. Box 3 shows some of the factors which can improve the motivation of the participants in the peer group.

PEIER RLVIEW METHOD)(OI.)('YY

Getting stuck with the process and the methods of peer review is a potential pitfall. For example, a group may restrict its actions to one phase of the peer review process only and, say, develop consensus criteria of targets without evaluating whether the criteria are followed, or the group may be continually involved in gathering, analysing, and exchanging data but have little idea of the direction of change. This is likely to create an atmosphere of non-commitment. The effect is similar if data are aggregated in a way that does not provide specific information for individual practices or care providers. Some groups may work too long on the same subject or use the same method again and again; as a result the process eventually becomes tedious. Further piftalls are having meetings without a clear programme and participants' lack of specific skills for peer review, such as communicating in a group or resolving conflicts, when the meetings are likely to become chaotic and unsatisfying. ${ }^{36}$

Experience from the projects in the Netherlands, the Republic of Ireland, and Germany suggests the importance of varying the peer review methods used and the topics 
discussed. A well designed programme for six or 12 months with variation of topics and well tested methods and with clear arrangements on each participant's responsibilities will stimulate motivation and involvement. ${ }^{239}$ Each meeting should have a more or less fixed structure - to help participants to concentrate on the content rather than the method or the structure of the meeting. Specific, well delineated topics should be selected, which can be handled in a relatively short time to prevent the peer review becoming boring. A group may even address several topics at the same time. For instance, setting targets for diabetes care may be started while implementation of improvements in the organisation of prevention takes place.

Peer review demands specific participants' skills - for example, in selecting suitable problems, handling guidelines and criteria, setting objectives for improvement, applying methods for data collection, giving and receiving adequate feedback, constructively communicating and working as a group, developing and implementing plans for change, and giving mutual support in achieving these changes. When the group first gets together time should be allocated for training of these skills by using simple, nonthreatening examples so that participants gain confidence. Specific attention should be given to handling disagreements - for instance, on the selected topics, the criteria for good quality, or the necessary changes in practice.

Finally, it is important not only that aggregated data (at the group, practice, or department level) are used for peer review but also that individual performance is discussed critically. It may seem threatening in the beginning, but will be much more satisfying in the long run.

\section{PROCESS OF CHANGE}

One of the great difficulties is in using guidelines and criteria, adhering to them, and achieving agreed changes in practice performance. Participants who may have worked for many years in isolation and without feedback on their style of working will each have developed their own guidelines for good practice. They accept that care providers can each have their own way of tackling problems, and being faced with different approaches and having mistakes pointed out is often not appreciated or may even be denied (for example, “guidelines don't apply to everyday practice, every patient is different and requires a different approach, my patients are pleased with my way of doing things").

In many peer review groups there is a noncommittal attitude to changing performance that is difficult to break down. Even when deviations from agreed criteria are admitted, there may be a reluctance to draw conclusions. Colleagues tend not to question each other on this and quickly accept that personal preferences differ and that everyone may continue to act according to that preference. To help counter this tendency, participants may be asked to clarify their aims in taking part in the peer review. Is the peer review a personal reflection on individual performance or do deviations of the agreed criteria imply the need for corrections, with colleagues acting as a superintending body?

It is also crucial to allow sufficient time for change within the peer review process - at least the same as that given to setting criteria or to the audit of actual care. Time should be set aside for identifying the barriers to change, which may be related to the care providers and their characteristics but more often to the setting in which they work ${ }^{17} 27$; for developing a plan for improvement with specific interventions; for managing the change process well; and for evaluating the results. Giving each other support to achieve changes is a crucial aspect of the peer review process. This includes discussing alternatives, demonstrating new skills to each other, collaboration on seeking solutions for specific problems faced by some of the participants, reminding and stimulating each other, and also rewarding each other for achieving the targets. These are all important opportunities for making peer review an effective as well as a pleasurable experience.

\section{ORGANISATION, STRUCTURES, AND}

CONDITIONS

Finally, to manage peer review well, and to stimulate motivation and involvement of the participants, certain organisational conditions have to be fulfilled, as follows.

- A long term plan of meetings, the topics to be discussed, and arrangements for attendance

- Continuity: regular meetings, preferably once a fortnight or once a month

- Clear arrangements for coordination, responsibilities of each participant, homework, minutes, etc

- A quiet, task-oriented location, with equipment and materials available

- Sufficient time for working (about two hours without major disturbances) and for informal contact before and after the meetings.

Facilitating and supervising peer review Groups or teams which start with peer review generally need supervision at the beginning. One of the participants should have some leadership skills, should know how to handle the group functioning, and should be able to structure the programme and apply various peer review methods. Training courses for peer group leaders or moderators have been successfully set up in Europe, and participants in these courses proved to be sufficiently skilled and prepared for their task after a short course and regular follow up meetings.

Another important condition for implementing peer review in local and practice settings is that it should fit within the normal structures for supporting care providers and practices on quality assurance and continuous medical education. Special facilitators attached to these structures may be available to provide information, materials, methods and support in setting up peer review. In the 
Netherlands there is a structure for quality improvement with regional and local coordinators, in the Republic of Ireland a team of district tutors; in the United Kingdom the audit facilitators involved in the medical audit advisory groups might adopt this new and challenging task. Evidence comes from the Netherlands in which a new method for peer review of clinical performance was disseminated in two counties, each with about 600 GPs. In one county the new method was posted to local coordinators for quality improvement, in the other two GP facilitators contacted all local group representatives and introduced the materials. Evaluative questionnaires after these interventions disclosed that the method was received in the first county, by $14 \%$ of the GPs and in the second by $49 \%{ }^{+1}$

\section{Conclusions}

The experiences so far have shown that peer review in local or regional groups or teams of care providers can be a valuable and effective method for quality improvement and change in health care that fits well into new views on medical audit and continuous quality improvement. It can also be linked to research findings on effective behaviour change in health care, which emphasise the importance of peer influence in the process of change. Achieving real and lasting improvements in the quality of care is becoming a key issue for quality assurance in health care. Peer review may be one of the preferred models for improvement and change in primary care in many countries. It may also be effective when applied by hospital departments or teams. To be effective, however, it must be well prepared and well organised. The introduction and motivation of participants should be gradual and should include teaching basic peer review skills. Clear arrangements on the aims of peer review and on the use of criteria should be made, and well-designed methods should be used. ${ }^{2}$ Managed well, peer review can become a method of lifelong learning, consistent with the reflection of Goethe, 200 years ago, that "the most fruitful lesson is the conquest of one's own error. Whoever refuses to admit error may be a great scholar, but he is not a great learner."

I McIntyre N, Popper K. The critical attitude in medicine: the need for a new ethics. BMF 1983;287:1919 23.

2 Grol R, Lawrence M. Quality improvement by peer review. Oxford: Oxford University Press: in press.

3 Winkler J, Lohr K, Brook R. Persuasive communication and medical technology assessment. Arch Interm Med and medical techn

4 Greer A. The state of the arts versus the state of the science. The diffusion of new medical technologies into practice. The diffusion of new medical technologies into

5 Flora J, Farquhar J. Methods of message design: experiences from the Standard Five Project. Scand $f$ Prim Care Suppl 1988;1:41-80.

6 Lomas J, Enkin M, Anderson G, et al. Opinion leaders v audit and feedback to implement practice guidelines. fAMA 1991;265:2202-7.

7 Lomas J. Teaching doctors old (and not so old) new tricks: effective ways to implement research findings. Hamilton, Ontario: 1993. (CHEPA Working Paper 93-4.)
8 Mittman B, Tonesk X, Jacobson P. Implementing clinical practice guidelines: social influence strategies and practice guidelines: social influence strategies and

9 Rogers E. Diffusion of imnerations. New York: Free Press. 1983.

10 Stocking B. Promoting change in clinical care. (utality in Health Care 1992;1:56-60.

1 Fox R, Mazmanian P, Putnam R. Changing and learning in the lives of physicians. New York: Praeger, 1989

12 Kotler P, Roberto E. Sociale marketting. Utrecht: Her Spectrum, 1991

13 Sommers L, Sholty R, Sheperd R, it al. Physician nvolvement in quality assurance Med 1984;12:1115-34

14 Grol R, Mokkink M. Schellevis F. The effects of peer

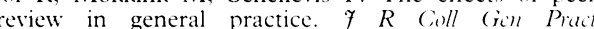
1988:38:10-3

15 Lomas J, Haynes R. A taxonomy and critical review of tested strategies for the application of clinical practice recommendations: from "official" to "individual" clinical policy. In: Implementing preventive services. Battista R, Lawrence R, eds. Am F Prov Mcd 1988;4:77 95.

16 Soumerai S, McLaughlin T, Avorn J. Quality assurance for rug prescribing. Ouality Assurance in Health Car $1990 ; 2: 37-58$.

17 (Grol R. Implementing guidelines in general practice care Oluality in Health Care 1992;1:184-91.

18 Mugford M, Banfield P, O'Hanlon M. Effects of feedback of information on clinical practice: a review. BMIY $1991 \cdot 303: 398-402$

19 Buntinx F, Winkens R, Grol R, Knottnerus A. Influencing diagnostic and preventive performance in ambulatory care by feedback and reminders: a review. Fam Prac 1993;10:219-28

20) Wensing M, Grol R. Single and combined strategies for implementing changes in primary care: a literature review. Int f Quality in Health Care 1994;6:115-32

21 Branthwaite A, Ross A, Henshaw A, Davic C. Contiming education for general practitioners. London: Royal College of General Practitioners 1988. (Occasional paper 38.)

22 Shirriffs G. Continuing educational requirements for general practitioners in Grampian. $\mathcal{F} R$ Coll (i'll Prait general practition

23 Owen P, Allerly L, ot al. General practitioners continuin medical education within and outside their practice. $B M I \%$ 1989;299:238-40

24 Forrest J, McKenna M, Stanley I, ot al. Continuing education: a survey among general practitioners. Fam Pract 1989;6:98-107

25 Pickup A, Mee L, Hedley A. Obstacles to continuin education. F $R$ Coll Gen Pract 1983;33:799-801

26 Irvine D. Managing for quality in general practice. L ondon: King's Fund, 1990

27 Berwick D. Continuous improvement as an ideal in health care. N Engl f Med 1989;320:53-6.

28 Berwick D, Enthoven A, Bunker J. Quality management in the NHS: the doctor's role. I. BMF 1992;304:2359.

29 North of England Study of Standards and Performance in General Practice. Medical audit in general practice. I Effects on doctors' clinical behaviour for common childhood conditions. BMF 1992;304:1480 4

30 Verby J, Holden P, Davies R. Peer review of consultation in primary care: the use of audiovisual recordings. $B M$ $1979 ; 1: 1686-8$

31 Deuschle J, Alvarez B, Logsdon DN, it al. Physician performance in a prepaid health insurance plan of Greater New York. Med Care 1982;2:127-42

32 Irvine D, Irvine S. Making schse of audit. Oxford: Radcliffe Medical Press, 1991.

33 Grol R. Peer review in primary care. Oual Assur Hialth (iur 1990;2:119-26.

34 Grol R. National standard setting for quality of care in general practice: attitudes of general practitioners and response to a set of standards. Br. . G Gill Prac 1990;40:361-4

35 Verblackt $\mathrm{H}$, Grol R. Intercollegiale toctsing in deskundigheidsbevordering in huisartsgroepon. Nijmegen University of Nijmegen, 1992

36 Newton J, Hutchinson A, Steen N, Russell I, Haimes E. Educational potential of medical audit: observations from a study of small groups setting standards. Quality in Hcalth Care 1992;1:256-9.

37 Grol R, Wensing M, Jacobs A, Baker R. Ouality assurano in general practice. The state of the ant in Europi. Utrecht . 1993

38 Bahrs O, Andres E, Gerlach F, Szecsenyi J, Weiß-Plumever M. Hausärtzliche Qualitätszirkel in Deutschland ein
Ubberblick. Zeitschrift für Allgemeinmedizin 1993; Uberblick.

39 Bahrs O, Gerlach F, Szecsenyi J, eds. Artzliche Qualitütszirkel. Köln: Deutscher Ärtze-Verlag, 1994

40 Ruprecht T. Von der Qualitätssicherung zum Qualitätsmanagement. Zeitschrift für Allgemeinmedizin 1993 69:963-7.

41 Zwaard A, Dalhuysen J, Mokkink H, Grol R. Disscmination of guidelines and review methods for clinical performance among GPs. Nijmegen: WOK, 1994. 